\title{
Generalized second-order slip for unsteady convective flow of a nanofluid: a utilization of Buongiorno's two-component nonhomogeneous equilibrium model
}

https://doi.org/10.1515/nleng-2020-0005

Received Aug 4, 2018; accepted Sep 2, 2019.

\begin{abstract}
The unsteady convective boundary layer flow of a nanofluid along a permeable shrinking/stretching plate under suction and second-order slip effects has been developed. Buongiorno's two-component nonhomogeneous equilibrium model is implemented to take the effects of Brownian motion and thermophoresis into consideration. It can be emphasized that, our two-phase nanofluid model along with slip concentration at the wall shows better physical aspects relative to taking the constant volume concentration at the wall. The similarity transformation method (STM), allows us to reducing nonlinear governing PDEs to nonlinear dimensionless ODEs, before being solved numerically by employing the Keller-box method (KBM). The graphical results portray the effects of model parameters on boundary layer behavior. Moreover, results validation has been demonstrated as the skin friction and the reduced Nusselt number. We understand shrinking plate case is a key factor affecting non-uniqueness of the solutions and the range of the shrinking parameter for which the solution exists, increases with the first order slip parameter, the absolute value of the second order slip parameter as well as the transpiration rate parameter. Besides, the second-order slip at the interface decreases the rate of heat transfer in a nanofluid. Finally, the analysis for no-slip and first-order slip boundary conditions can also be retrieved as special cases of the present model.
\end{abstract}

Keywords: Unsteady convective flow; Nanofluid; Buongiorno's model; Shrinking/stretching plate; Second-order slip; Dual solutions; Nanoparticles concentration boundary condition

\section{Introduction}

Today, nanofluids play a bold role in modern industry and that important role comes from their great capability in thermal conductivity and capacity and also other physical characteristics. Having a low heat transfer in a fluid would cause limited heat transfer and can lead to limited heat transfer efficiency. Producing a solution that comprises of suspending solid metal components will enhance the thermal conductivity characteristics of the base fluid. This approach is one of the state-of-the-art procedure that has been exploited to increase the heat transfer coefficient. Due to the high thermal conductivity of metal particles, adding them to a fluid would increase the thermal conductivity and also heat transfer of the resultant mixture fluid [1-5]. This phenomenon attracts a lot of attention such as of Oztop and Abu-Nada [6], Buongiorno [7], Tiwari and Das [8], Dinarvand et al. [9], Nield and Kuznetsov [10], Grosan and Pop [11], Tamim et al. [12], Dinarvand et al. [13], Sheremet et al. [14] and Maïga et al. [15] to have deeper examination of the matter. What have been proved and still demand more research was that the presence of nano metal particle in a fluid will significantly increase the thermal conductivity and will ultimately improve the heat transfer feature on the fluid.

In Ref. [7], Buongiorno made a thorough research on convective transfer of nanofluids and concludes that, so far, there has not been a reasonable rationalization for the extraordinary increase in the thermal conductivity and viscosity in the resultant nanofluids. Buongiorno's main concentration was on additional improvement which occurs in connective situations. He discussed that many researchers try to justify that abnormal increase in the heat transfer. Some scientists consider the suspended metal

University, Tehran, Iran, E-mail: sae.dinarvand@iauctb.ac.ir; saeed_dinarvand@yahoo.com

Mohammad Eftekhari Yazdi, Mechanical Engineering Department, Central Tehran Branch, Islamic Azad University, Tehran, Iran
Seyed Mahdi Mousavi, Mechanical Engineering Department, Cen*Corresponding Author: Saeed Dinarvand, Mechanical Engineering Department, Central Tehran Branch, Islamic Azad
This work is licensed under the Creative Commons 
particles as a reason for that increase, but Buongiorno disputes this reason and argues that this suspension is minutia to justify the observed enhancement. Another group contemplates turbulence as a potential explanation, however Buongiorno asserts that there would be no change in turbulence as nanoparticles appear in the nanofluids, so turbulence could not justify the enhancement in the heat transfer. Another untenable justification for heat transfer enhancement is considering the rotation of particles. Buongiorno has worked out to calculate this effect and proved that the rotation of the particles is too small to proffer a satisfactory explanation for the observed heat transfer improvement. By considering the suspension of particles, particle rotation, and turbulence as diminutive effects, which cannot rational the diminutive heat transfer improvement, Buongiorno constructed a novel formulation based on the mechanics of the nanoparticle/basefluid relative velocity. He came up with a relative speed and named it the slip velocity, and suggested that the velocity of nanoparticles can be seen as the summation of velocity on the base fluid and the slip velocity [7]. Buongiorno then regarded seven different slip components, including: inertia, Brownian diffusion, thermophoresis, diffusiophoresis, Magnus effect, fluid drainage, and gravity settling. He investigated each on these seven velocities separately and deduced that when there is no turbulence, Brownian diffusion and the thermophoresis are the most dominant effects. He developed the conservation equations with regard to these two results. After proposing the model by Buongiorno [7], recently several researchers, including Nield and Kuznetsov [10], Bachok et al. [16], Pop and Khan [17], Kuznetsov and Nield [18], Dinarvand et al. [19] and others [20-23], developed their work based on Buongiorno's model.

In no-slip flow, the velocity at the wall of solid container is zero, so that fluid components and the wall have equal velocity. However, there are some circumstances in which this assumption is not applicable, particularly in the case of nanoparticles. Hence, different researchers try to address slip boundary conditions for special problems [24-26]. The subject of slip is much practical in medical engineering such as making artificial arteries and heart balloons also in the processes of pipe and wire productions, as well as extrusion of polymeric materials. Rosca and Pop [27] examined second order slip suggested by $\mathrm{Wu}$ [28], to scrutinize the varying surface temperature. In Ref. [29], Rosca and Pop inquire another condition involving second order slip condition to examine surface heat flux. They found the high influence of second order slip on the properties of flow and heat transfer.
Considering these facts, the authors of this paper studied the effects of second-order slip on unsteady convective boundary layer flow of a nanofluid on a permeable shrinking/stretching sheet with suction in surface and to include the effects of Brownian motion and thermophoresis for the nanofluids, the two-component nonhomogeneous equilibrium model of Buongiorno is used. The similarity solution, which relies on nine independent dimensionless components, was also deployed. In order to solve the derived equations numerically, the Keller-box method was used. In this paper, the results and discourses are mainly concentrated on: (1) the multiple solutions [30-32], (2) the boundary layers behavior and (3) the skin friction and heat transfer.

\section{Problem formulation and model development}

\subsection{Obtaining the mathematical formulation}

Assuming the unsteady two-dimensional flow of a nanofluid driven by a stretching/shrinking flat sheet (Figure 1). The velocity of plate is assumed as $\lambda u_{w}(x)$, and $\lambda$ is shrinking parameter that $\lambda>0$ and $\lambda<0$ indicative stretching sheet and shrinking sheet, respectively. Regarding $\mathrm{x}$ and $\mathrm{y}$ axes, we consider $\mathrm{x}$-axis along the sheet and the $y$-axis is perpendicular to the surface of the sheet, it's positive from the surface of sheet toward the nanofluid flow (Fig. 1). Here, the sheet to be permeable with $v_{w}^{*}(t)$ as the identical mass flux at wall, where $v_{w}^{\star}(t)<0$ and $v_{w}^{*}(t)>0$ represent suction and injection, respectively. It is also assumed that the plate has a heat source with unchanging heat flux $\left(q_{w}\right)$. Referring to Bonjourno's model, the mathematical relations are as follows [7]

$$
\begin{gathered}
\nabla \cdot V=0 \\
\rho_{f}(V . \nabla V)=\mu \nabla^{2} V, \\
(\rho c)_{f}(V . \nabla T)=k \nabla^{2} T+(\rho c)_{p}\left[D_{B} \nabla C . \nabla T+\left(\frac{D_{T}}{T_{\infty}}\right) \nabla T \cdot \nabla T\right],
\end{gathered}
$$

$$
V . \nabla C=D_{B} \nabla^{2} C+\left(\frac{D_{T}}{T_{\infty}}\right) \nabla^{2} T .
$$

In Relations (1)-(4), $V=(u, v)$ denotes velocity, $T$ is temperature and $C$ is the nanoparticle concentration. Moreover, density of base fluid is shown with $\rho_{f}, \mu$ and $k$ are 
the viscosity and effective thermal conductivity of the nanofluid, respectively. $D_{B}$ represent the Brownian diffusion coefficient and $D_{T}$ is thermophoretic diffusion coefficient, and the $(\rho c)_{f}$ and $(\rho c)_{p}$ are the heat capacity of the base fluid and effective heat capacity of the solid particle, respectively. A detailed explanation of equations (3) and (4) can be find on [7] and [10].

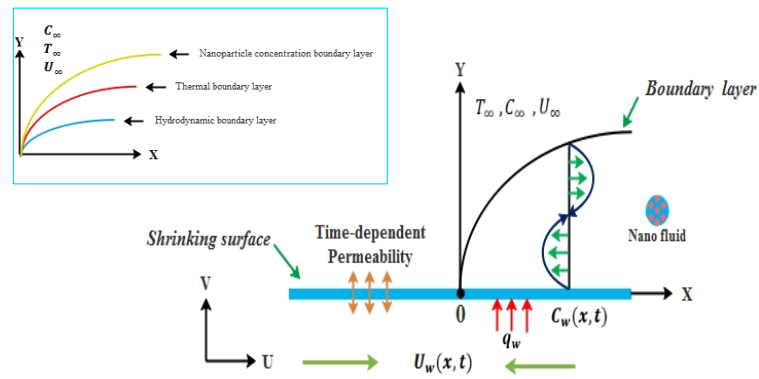

Figure 1: Schematic diagram of the physical model and the typical patterns of boundary layers

According to scale analysis, Eqs.(1)-(4) can be written as:

$$
\begin{gathered}
\frac{\partial u}{\partial x}+\frac{\partial v}{\partial y}=0 \\
\frac{\partial u}{\partial t}+u \frac{\partial u}{\partial x}+v \frac{\partial u}{\partial y}=v \frac{\partial^{2} u}{\partial y^{2}}, \\
\frac{\partial T}{\partial t}+u \frac{\partial T}{\partial x}+v \frac{\partial T}{\partial y}=\alpha \frac{\partial^{2} T}{\partial y^{2}} \\
+y\left[D_{B}\left(\frac{\partial C}{\partial y} \frac{\partial T}{\partial y}\right)+\left(\frac{D_{T}}{T_{\infty}}\right)\left(\frac{\partial T}{\partial y}\right)^{2}\right] \\
\frac{\partial C}{\partial t}+u \frac{\partial C}{\partial x}+v \frac{\partial C}{\partial y}=D_{B} \frac{\partial^{2} C}{\partial y^{2}}+\left(\frac{D_{T}}{T_{\infty}}\right) \frac{\partial^{2} T}{\partial y^{2}}
\end{gathered}
$$

The fluid thermal diffusivity $\alpha$, and nanofluid heat capacit y $y$ are written as:

$$
\alpha=\frac{k}{(\rho c)_{f}}, \quad y=\frac{(\rho c)_{p}}{(\rho c)_{f}} .
$$

Definition of the stream function $\psi(x, y)$ as:

$$
u=\frac{\partial \psi}{\partial y}, \quad v=-\frac{\partial \psi}{\partial x} .
$$

which satisfies the continuity equation (Eq. (5)) identically leaving the remaining three equations i.e., Eqs. (6)-(8), in the following forms

$$
\frac{\partial^{2} \psi}{\partial y \partial t}+\frac{\partial \psi}{\partial y} \frac{\partial^{2} \psi}{\partial x \partial y}-\frac{\partial \psi}{\partial x} \frac{\partial^{2} \psi}{\partial y^{2}}=v \frac{\partial^{2} u}{\partial y^{2}},
$$

$$
\begin{gathered}
\frac{\partial T}{\partial t}+\frac{\partial \psi}{\partial y} \frac{\partial T}{\partial x}-\frac{\partial \psi}{\partial x} \frac{\partial T}{\partial y}=\alpha \frac{\partial^{2} T}{\partial y^{2}} \\
+y\left[D_{B}\left(\frac{\partial C}{\partial y} \frac{\partial T}{\partial y}\right)+\left(\frac{D_{T}}{T_{\infty}}\right)\left(\frac{\partial T}{\partial y}\right)^{2}\right], \\
\frac{\partial C}{\partial t}+\frac{\partial \psi}{\partial y} \frac{\partial C}{\partial x}-\frac{\partial \psi}{\partial x} \frac{\partial C}{\partial y}=D_{B} \frac{\partial^{2} C}{\partial y^{2}}+\left(\frac{D_{T}}{T_{\infty}}\right) \frac{\partial^{2} T}{\partial y^{2}} .
\end{gathered}
$$

Eqs. (5)-(8) exposed to the boundary and initial conditions

$$
\begin{aligned}
& t<0: \quad u=0, v=0, T=T_{\infty}, C=C_{\infty} \text { forany } x, y . \\
& \left.\begin{array}{ll}
t \geq 0: & u=\lambda u_{w}(x)+u_{s l i p}(x), v=v_{w}^{\star}(t) \\
& -k_{f} \frac{\partial T}{\partial y}=q_{w}, D_{B} \frac{\partial C}{\partial y}+\frac{D_{T}}{T_{\infty}} \frac{\partial T}{\partial y}=0
\end{array}\right\} \quad \text { at } y=0, \\
& u \rightarrow 0, T \rightarrow T_{\infty}, C \rightarrow C_{\infty} \text {, as } y \rightarrow \infty .
\end{aligned}
$$

Regarding Wu [28], velocity of slip $u_{\text {slip }}(x)$ at the plate surface is driven as:

$$
\begin{aligned}
& u_{\text {slip }}(x)=\frac{2}{3}\left(\frac{3-\sigma l^{2}}{\sigma}-\frac{3}{2} \frac{1-l^{2}}{k n}\right) \delta \frac{\partial u}{\partial y} \\
& -\frac{1}{4}\left(l^{4}+\frac{2}{k n^{2}}\left(1-l^{2}\right)\right) \delta^{2} \frac{\partial^{2} u}{\partial y^{2}}=M \frac{\partial u}{\partial y}+N \frac{\partial^{2} u}{\partial y^{2}},
\end{aligned}
$$

where

$$
\begin{aligned}
& M=\frac{2}{3}\left(\frac{3-\sigma l^{2}}{\sigma}-\frac{3}{2} \frac{1-l^{2}}{k n}\right) \delta, \\
& N=-\frac{1}{4}\left(l^{4}+\frac{2}{k n^{2}}\left(1-l^{2}\right)\right) \delta^{2},
\end{aligned}
$$

In Eqs. (15)-(16) kn represent the Knudsen number, $l=\min (1 / k n, 1), \sigma$ and $\delta$ indicates the coefficient of momentum accommodation $(0 \leq \sigma \leq 1)$ and the molecular mean free path, respectively. $l$ would be $0 \leq l \leq 1$ for all values of Knudsen number. As $\delta$ is always positive it leads $N$ to be negative. Eq. (15) is been used by other researcher such as [30, 34], and lately by Rosca and Pop [24, 29].

It is worth mentioning that we assume the flux of nanoparticles at the surface equal to zero and it is because of the effect of effect of thermophoresis. Hence, we have

$$
D_{B}(\partial C / \partial y)+\left(D_{T} / T_{\infty}\right)(\partial T / \partial y)=0,
$$

denotes that due to thermophoresis the nanoparticles flux is zero.

In order to obtain similarity solutions, the temperature at the wall $T_{w}(x, t)$, and the nanoparticles volume fraction at the wall $C_{w}(x, t)$ are assigned in the following form

$$
T_{w}(x, t)=T_{\infty}+\frac{q_{w} l}{k \operatorname{Re}^{1 / 2}}, C_{w}(x, t)=C_{\infty}+\frac{a x}{(1-c t)^{2}} .
$$




\subsection{Similarity transformation}

We need a similarity transformation to solve Eqs. (11)-(13) subject to boundary conditions (14), for this purpose considering $u_{w}(x, t)=a x(1-c t)^{-1}$ in which $a$ and $c$ are positive constants. Besides, it can be defined a dimensionless normal distance $\eta$ given by

$$
\eta=\left(\frac{a}{v(1-c t)}\right)^{\frac{1}{2}} y
$$

We used the equations (20) to deploy similarity solution and solve Eqs. (11)-(13).

$$
\begin{aligned}
& \psi(x, y, t)=\left(\frac{v a}{1-c t}\right)^{\frac{1}{2}} x f(\eta), \\
& \theta(\eta)=\frac{T-T_{\infty}}{\left[\left(q_{w}[(1-c t) v / a]^{1 / 2}\right) / k\right]}, \quad \phi(\eta)=\frac{C-C_{\infty}}{C_{w}-C_{\infty}} .
\end{aligned}
$$

Considering the streamline Eq. (10), it can be obtained as

$$
u=\frac{a x}{(1-c t)} f^{\prime}(\eta), v=-\left(\frac{v a}{1-c t}\right)^{\frac{1}{2}} f(\eta)
$$

In which the derivation are with respect to $\eta$. We defined $v_{w}^{*}(t)$ as (22) in order to be able to solve Eqs. (11)-(13) with similarity solution.

$$
v_{w}^{*}(t)=-\left(\frac{v a}{1-c t}\right)^{\frac{1}{2}} V_{w}
$$

wherein $V_{w}$ describes the rate of transpiration so that $V_{w}>$ $0, V_{w}<0$ and $V_{w}=0$ are relate to suction, injection and an impermeable surface, respectively. Eqs. (11)-(13) simplified to nonlinear ODE by using the similarity transformations (19) and (20) and are rewritten as follows

$$
\begin{aligned}
& f^{\prime \prime \prime}+f f^{\prime \prime}-f^{\prime 2}-A\left(f^{\prime}+\frac{1}{2} \eta f^{\prime \prime}\right)=0, \\
& \frac{1}{P r} \theta^{\prime \prime}+f \theta^{\prime}-f^{\prime} \theta-A\left(2 \theta+\frac{1}{2} \eta \theta^{\prime}\right)+N b \theta^{\prime} \phi^{\prime}+N t \theta^{\prime 2}=0,
\end{aligned}
$$

$\frac{1}{L e} \phi^{\prime \prime}+f \phi^{\prime}-f^{\prime} \phi-A\left(2 \phi+\frac{1}{2} \eta \phi^{\prime}\right)+\frac{1}{L e} \frac{N t}{N b} \theta^{\prime \prime}=0$,

and the transformed boundary conditions as follows

at $\eta=0 \quad: \quad f(0)=V_{w}, f^{\prime}(0)=\lambda+m f^{\prime \prime}(0)+n f^{\prime \prime \prime}(0)$, $\theta^{\prime}(0)=-1, N b \phi^{\prime}(0)+N t \theta^{\prime}(0)=0$

as $\eta \rightarrow \infty: f^{\prime}(\infty) \rightarrow 0, \theta(\infty) \rightarrow 0, \phi(\infty) \rightarrow 0$, the first order slip $(m)$ and second order slip $(n)$ given by

$$
\begin{aligned}
m & =\left(\frac{a}{v(1-c t)}\right)^{\frac{1}{2}} M \\
& =\left(\frac{a}{v(1-c t)}\right)^{\frac{1}{2}}\left\{\frac{2}{3}\left(\frac{3-\sigma l^{2}}{\sigma}-\frac{3}{2} \frac{1-l^{2}}{k n}\right) \delta\right\}>0, \\
n & =\left(\frac{a}{v(1-c t)}\right) N \\
& =\left(\frac{a}{v(1-c t)}\right)\left\{-\frac{1}{4}\left(l^{4}+\frac{2}{k n^{2}}\left(1-l^{2}\right)\right) \delta^{2}\right\}<0,
\end{aligned}
$$

in Eqs.(23)-(25) $A$ is unsteadiness parameter, $P r$ is the Prandtl number, $L e$ is the Lewis number, $N b$ and $N t$ represent the Brownian motion and the thermophoresis parameter, respectively and defined as

$$
\begin{aligned}
& \operatorname{Pr}=\frac{v}{\alpha}, L e=\frac{v}{D_{B}}, A=\frac{c}{a}, \\
& N b=\frac{y D_{B}\left(C_{w}-C_{\infty}\right)}{v}, N t=\frac{y D_{T}\left(T_{w}-T_{\infty}\right)}{v T_{\infty}} .
\end{aligned}
$$

\subsection{Quantities of engineering interest}

Among many quantities in the formulation of the problem, three of them including skin friction coefficient $C_{f}$, the Nusselt number $\mathrm{Nu}$ and the Sherwood number $\mathrm{Sh}$ are noteworthy in empirical cases. These parameters are defined as follow

$$
\begin{aligned}
& C_{f}=\frac{\tau_{w}}{\rho\left(\frac{a x}{(1-c t)}\right)^{2}}, N u=\frac{(\sqrt{v(1-c t) / a}) q_{w}}{k_{f}\left(T_{w}-T_{\infty}\right)}, \\
& S h=\frac{(\sqrt{v(1-c t) / a}) q_{m}}{D_{B}\left(C_{w}-C_{\infty}\right)},
\end{aligned}
$$

where $\tau_{w}$ is the wall shear stress, $q_{w}$ and $q_{m}$ is heat flux and nanoparticle mass flux of the wall, which as

$\tau_{w}=\mu\left(\frac{\partial u}{\partial y}\right)_{y=0}, q_{w}=-k_{f}\left(\frac{\partial T}{\partial y}\right)_{y=0}, q_{m}=-D_{B}\left(\frac{\partial C}{\partial y}\right)_{y=0}$.

Based on similarity equations of (20), and considering $R e_{x}=a x^{2} / v(1-c t)$ which is local Reynold number, $C_{f}$, $\mathrm{Nu}$ and $\mathrm{Sh}$ would be as

$$
R e_{x}^{1 / 2} C_{f}=f^{\prime \prime}(0), N u=\frac{1}{\theta(0)}, S h=-\phi^{\prime}(0) .
$$

\section{Stability analysis}

To evaluate the physical realization of the first and second solution, stability analysis in been carried out [35]. Considering the procedure in [36], variable $\tau$ that is associated 
with the initial value problem is introduced. Therefore, the new variables are

$$
\begin{aligned}
& u=\frac{a x}{(1-c t)} f^{\prime}(\eta, \tau), v=-\left(\frac{v a}{1-c t}\right)^{\frac{1}{2}} f(\eta, \tau), \\
& \theta(\eta, \tau)=\frac{T-T_{\infty}}{\left[\left(q_{w}[(1-c t) v / a]^{1 / 2}\right) / k\right]}, \\
& \phi(\eta, \tau)=\frac{C-C_{\infty}}{C_{w}-C_{\infty}}, \quad \eta=\left(\frac{a}{v(1-c t)}\right)^{\frac{1}{2}} y, \quad \tau=a t .
\end{aligned}
$$

replacing (32) into (5)-(8), we would have

$$
\begin{aligned}
& \frac{\partial^{3} f}{\partial \eta^{3}}+f \frac{\partial^{2} f}{\partial \eta^{2}}-\left(\frac{\partial f}{\partial \eta}\right)^{2}-A\left(\frac{\partial f}{\partial \eta}+\frac{1}{2} \eta \frac{\partial^{2} f}{\partial \eta^{2}}\right)-\frac{\partial^{2} f}{\partial \eta \cdot \partial \tau}=0 \\
& \frac{1}{\operatorname{Pr}} \frac{\partial^{2} \theta}{\partial \eta^{2}}+f \frac{\partial \theta}{\partial \eta}-\frac{\partial f}{\partial \eta} \theta-A\left(2 \theta+\frac{1}{2} \eta \frac{\partial \theta}{\partial \eta}\right) \\
& +N b \frac{\partial \theta}{\partial \eta} \frac{\partial \phi}{\partial \eta}+N t\left(\frac{\partial \theta}{\partial \eta}\right)^{2}-\frac{\partial \theta}{\partial \tau}=0 \\
& \frac{1}{L e} \frac{\partial^{2} \phi}{\partial \eta^{2}}+f \frac{\partial \phi}{\partial \eta}-\frac{\partial f}{\partial \eta} \phi-A\left(2 \phi+\frac{1}{2} \eta \frac{\partial \phi}{\partial \eta}\right) \\
& +\frac{1}{L e} \frac{N t}{N b} \frac{\partial^{2} \theta}{\partial \eta^{2}}-\frac{\partial \phi}{\partial \tau}=0,
\end{aligned}
$$

under these boundary conditions

$$
\begin{aligned}
& f(0, \tau)=V_{w}, \frac{\partial f}{\partial \eta}(0, \tau)=\lambda+m \frac{\partial^{2} f}{\partial \eta^{2}}(0, \tau)+n \frac{\partial^{3} f}{\partial \eta^{3}}(0, \tau) \\
& \frac{\partial \theta}{\partial \eta}(0, \tau)=-1, N b \frac{\partial \phi}{\partial \eta}(0, \tau)+N t \frac{\partial \theta}{\partial \eta}(0, \tau)=0 \\
& \frac{\partial f}{\partial \eta}(\infty, \tau) \rightarrow 0, \theta(\infty, \tau) \rightarrow 0, \phi(\infty, \tau) \rightarrow 0
\end{aligned}
$$

As specified by Weidman [36], stability of the steady flow solution $f(\eta)=f_{0}(\eta), \theta(\eta)=\theta_{0}(\eta)$ and $\phi(\eta)=\phi_{0}(\eta)$ for Eqs. (5)-(8) is tested using the following

$$
\begin{gathered}
f(\eta, \tau)=f_{0}(\eta)+e^{-y \tau} F(\eta, \tau), \\
\theta(\eta, \tau)=\theta_{0}(\eta)+e^{-y \tau} G(\eta, \tau), \\
\phi(\eta, \tau)=\phi_{0}(\eta)+e^{-y \tau} H(\eta, \tau) .
\end{gathered}
$$

Which $y$ is an unknown eigenvalue parameter and $F(\eta, \tau)$, $G(\eta, \tau)$ and $H(\eta, \tau)$ are small compared to $f_{0}(\eta), \theta_{0}(\eta)$ and $\phi_{0}(\eta)$ respectively. Replacing (37) into Eqs. (33)-(35), we would have the following equations which are transformed into linear equations

$$
\begin{aligned}
& \frac{\partial^{3} F}{\partial \eta^{3}}+f_{0}^{\prime \prime} F-A\left(\frac{\partial F}{\partial \eta}+\frac{1}{2} \eta \frac{\partial^{2} F}{\partial \eta^{2}}\right) \\
& -\left(2 f_{0}^{\prime}-y\right) \frac{\partial F}{\partial \eta}-\frac{\partial^{2} F}{\partial \eta \cdot \partial \tau}=0,
\end{aligned}
$$

$$
\begin{aligned}
& \frac{1}{\operatorname{Pr}} \frac{\partial^{2} G}{\partial \eta^{2}}+f_{0} \frac{\partial G}{\partial \eta}+\theta_{0}^{\prime} F-f_{0}^{\prime} G-\theta_{0} \frac{\partial F}{\partial \eta}-A\left(2 G+\frac{1}{2} \eta \frac{\partial G}{\partial \eta}\right) \\
& +N b\left(\theta_{0}^{\prime} \frac{\partial H}{\partial \eta}+\phi_{0}^{\prime} \frac{\partial G}{\partial \eta}\right)+2 N t \theta_{0}^{\prime} \frac{\partial G}{\partial \eta}+y G-\frac{\partial G}{\partial \tau}=0 \\
& \frac{1}{L e} \frac{\partial^{2} H}{\partial \eta^{2}}+f_{0} \frac{\partial H}{\partial \eta}+\phi_{0}^{\prime} F-f_{0}^{\prime} H-\frac{\partial F}{\partial \eta} \phi_{0}-A\left(2 H+\frac{1}{2} \eta \frac{\partial H}{\partial \eta}\right) \\
& +\frac{1}{L e} \frac{N t}{N b} \frac{\partial^{2} G}{\partial \eta^{2}}+y H-\frac{\partial H}{\partial \tau}=0,
\end{aligned}
$$

Subsequently, the pertaining boundary conditions would be as

$$
\begin{aligned}
& F(0, \tau)=V_{w}, \frac{\partial F}{\partial \eta}(0, \tau)=\lambda+m \frac{\partial^{2} F}{\partial \eta^{2}}(0, \tau)+n \frac{\partial^{3} F}{\partial \eta^{3}}(0, \tau) \\
& \frac{\partial G}{\partial \eta}(0, \tau)=-1, N b \frac{\partial H}{\partial \eta}(0, \tau)+N t \frac{\partial G}{\partial \eta}(0, \tau)=0 \\
& \frac{\partial F}{\partial \eta}(\infty, \tau) \rightarrow 0, G(\infty, \tau) \rightarrow 0, H(\infty, \tau) \rightarrow 0
\end{aligned}
$$

With regard to Weidman et al. [36], we assign $\tau=0, F=$ $F_{0}(\eta), G=G_{0}(\eta)$ and $H=H_{0}(\eta)$ in order to achieve the linear eigenvalue problem (equations (42)-(44))

$$
\begin{aligned}
& F_{0}^{\prime \prime \prime}+f_{0}^{\prime \prime} F_{0}-A\left(F_{0}^{\prime}+\frac{1}{2} \eta F_{0}^{\prime \prime}\right)-\left(2 f_{0}^{\prime}-y\right) F_{0}^{\prime}=0, \\
& \frac{1}{P r} G_{0}^{\prime \prime}+f_{0} G_{0}^{\prime}+\theta_{0}^{\prime} F_{0}-f_{0}^{\prime} G_{0}-\theta_{0} F_{0}^{\prime}-A\left(2 G_{0}+\frac{1}{2} \eta G_{0}^{\prime}\right) \\
& +N b\left(\theta_{0}^{\prime} H_{0}^{\prime}+\phi_{0}^{\prime} G_{0}^{\prime}\right)+2 N t \theta_{0}^{\prime} G_{0}^{\prime}+y G_{0}=0, \\
& \frac{1}{L e} H_{0}^{\prime \prime}+f_{0} H_{0}^{\prime}+\phi_{0}^{\prime} F_{0}-f_{0}^{\prime} H_{0}-F_{0}^{\prime} \phi_{0}-A\left(2 H_{0}+\frac{1}{2} \eta H_{0}^{\prime}\right) \\
& +\frac{1}{L e} \frac{N t}{N b} G_{0}^{\prime \prime}+y H_{0}=0,
\end{aligned}
$$

with these boundary conditions

$$
F_{0}(0)=V_{w}, F_{0}^{\prime}(0)=\lambda+m F_{0}^{\prime \prime}(0)+n F_{0}^{\prime \prime \prime}(0), G_{0}^{\prime}(0)=-1 \text {, }
$$

$$
\begin{aligned}
& N b H_{0}^{\prime}(0)+N t G_{0}^{\prime}(0)=0, F_{0}^{\prime}(\infty) \rightarrow 0, G_{0}(\infty) \rightarrow 0, \\
& H_{0}(\infty) \rightarrow 0 .
\end{aligned}
$$

As claimed by Haris [31], the range of possible eigenvalues can be determined by relaxing a boundary condition on $F_{0}^{\prime}(\eta), G_{0}(\eta)$ or $H_{0}(\eta)$. For instance, we can select to relax the condition that $G_{0}(\eta) \rightarrow 0$ when $\eta \rightarrow \infty$. Thus, we are able to solve the Eqs. (42)-(45) for a constant value of $y$ with regard to the new condition $G_{0}(0)=1$.

\section{Numerical procedure and validation}

We have to solve a complex boundary value problem that has been represented in Eqs. (23)-(26) with nine governing 
parameters such as unsteadiness parameter $(A)$, shrinking parameter $(\lambda)$, mass suction velocity $\left(V_{w}\right)$, thermophoresis parameter $(\mathrm{Nt})$, Brownian motion parameter $(\mathrm{Nb})$, firstorder slip parameter $(m)$, second-order slip parameter $(n)$, Lewis number $(L e)$ and Prandtl number $(P r)$. Our numerical procedure is the Keller-box method (see Refs. [38-40]). Further, after converting Eqs. (23)-(25), to a system of firstorder ODEs, we can attempt to numerically solve them using finite difference method with central difference approximation. Then, the linearization process is performed with help of Newton's method. Finally, the resultant algebraic system is solved considering the boundary conditions by the block-tridiagonal elimination method. In this investigation, the pertinent mesh sizes $(\Delta \eta)$ were chosen to 0.001 along with a relative tolerance of 0.00001 , so that it has four decimal places accuracy. On the other hand, the far field boundary condition $\left(\eta_{\infty}\right)$ changes between 0.4 and 9 to successfully satisfying them. It is worth mentioning that, Pantokratoras [41] has alarmed that some graphical published results for the velocity and temperature profiles obtained by previous dear investigators are wrong due to do not approaching their dependent variables to the correct values at the edge of the boundary layer, perfectly.

In order to numerical validation of the problem, Table 1 compares the similarity value of the skin friction coefficient $\left(f^{\prime \prime}(0)\right)$ with previously published reports like Rosca and Pop [24] and Fang et al. [30], when $A=0$ and $\lambda=-1$. Table 1 proves that our numerical attitude is in perfect agreement with other previous publications. Therefore, it can be deduced that our numerical results are reliable and accurate.

\section{Results and discussion}

The unsteady convective boundary layer flow of a nanofluid with the utilization of Buongiorno's twocomponent nonhomogeneous equilibrium model has been studied numerically using the KBM. The influences of the second-order slip on heat and fluid flows are a major target for the present study. In this section, the results for justified values of parameters are obtained and discussed. The observations have been separated in three sections as: (1) the multiple solutions, (2) the boundary layers behavior: flow, thermal and concentrations fields, (3) the skin friction and heat transfer.

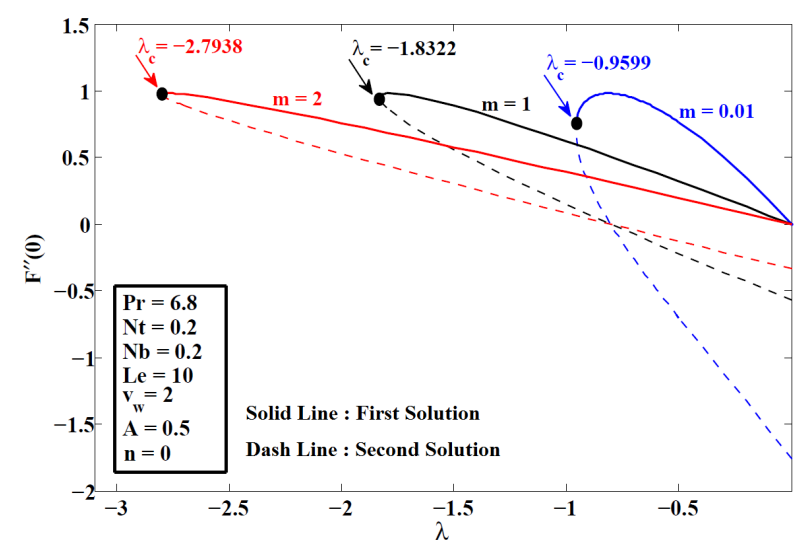

Figure 2: Variation of $f^{\prime \prime}(0)$ with the shrinking parameter $\lambda$ for different values of first-order slip parameter $m$.

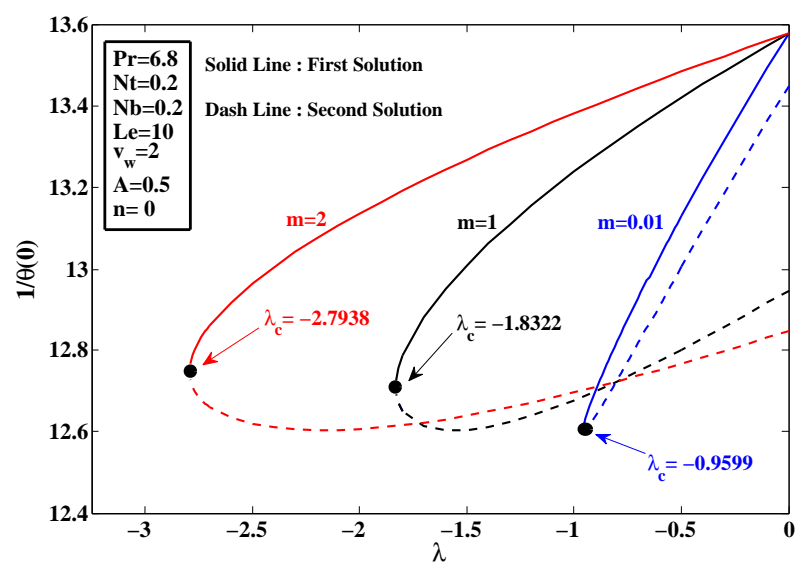

Figure 3: Variation of $1 / \theta(0)$ with the shrinking parameter $\lambda$ for different values of first-order slip parameter $m$

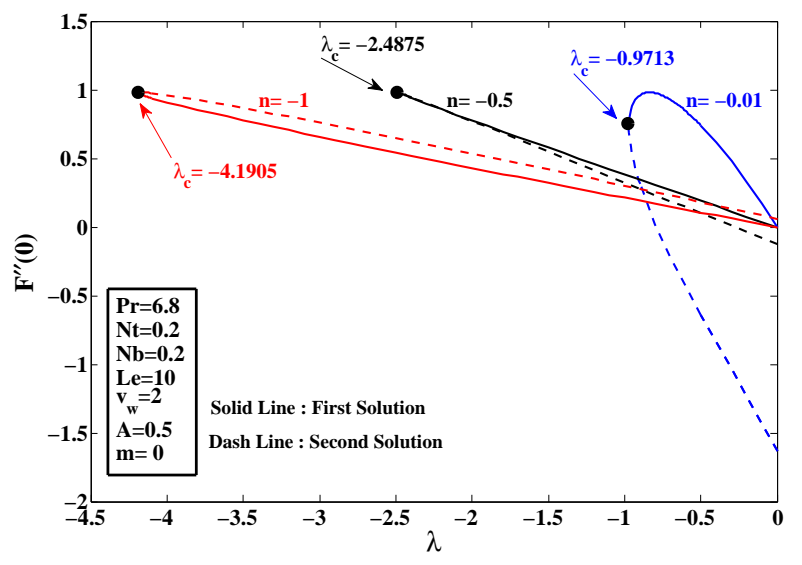

Figure 4: Variation of $f^{\prime \prime}(0)$ with the shrinking parameter $\lambda$ for different values of second-order slip parameter $n$ 
Table 1: The influence of the first-order slip parameter $(m)$, second-order slip parameter $(n)$ and transpiration rate parameter $\left(V_{w}\right)$ on $f^{\prime \prime}(0)$ for shrinking plate, and comparison with results of Rosca and Pop [24] and Fang et al. [30] for steady flow case $(A=0)$, when $\lambda=-1$.

\begin{tabular}{|c|c|c|c|c|c|c|c|c|}
\hline \multirow[t]{2}{*}{$v_{w}$} & \multirow[t]{2}{*}{$m$} & \multirow[t]{2}{*}{$n$} & \multicolumn{2}{|l|}{ Present study } & \multicolumn{2}{|l|}{ Rosca and Pop } & \multicolumn{2}{|l|}{ Fang et al } \\
\hline & & & Second Solution & First Solution & Second Solution & First Solution & Second Solution & First Solution \\
\hline \multirow[t]{2}{*}{2} & 1 & -1 & 0.25631035 & 0.29054789 & 0.2565 & 0.2905 & 0.2565 & 0.2905 \\
\hline & 1 & -2 & 0.22599336 & 0.18465687 & 0.2257 & 0.1846 & 0.2257 & 0.1847 \\
\hline \multirow[t]{2}{*}{3} & 1 & -1 & 0.20223417 & 0.23201653 & 0.2022 & 0.2320 & 0.2022 & 0.2317 \\
\hline & 1 & -2 & 0.18811181 & 0.13690542 & 0.1868 & 0.1369 & 0.1868 & 0.1371 \\
\hline
\end{tabular}

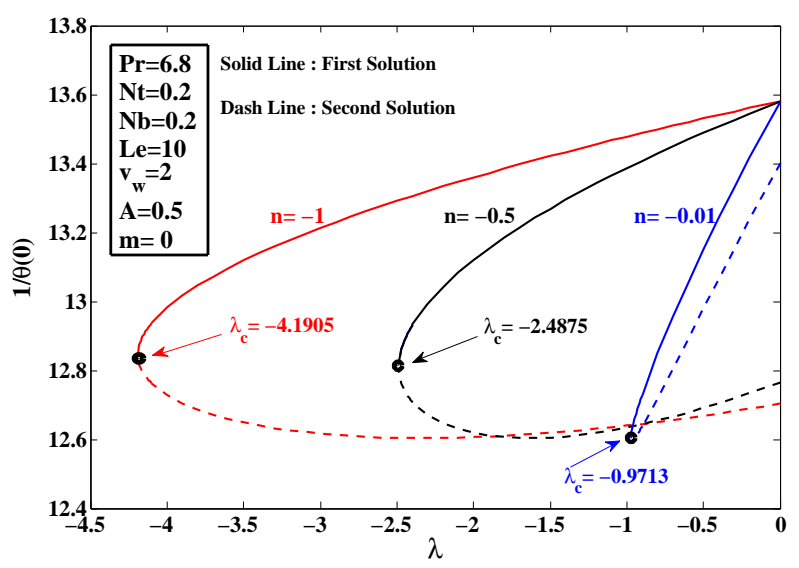

Figure 5: Variation of $1 / \theta(0)$ with the shrinking parameter $\lambda$ for different values of second-order slip parameter $n$

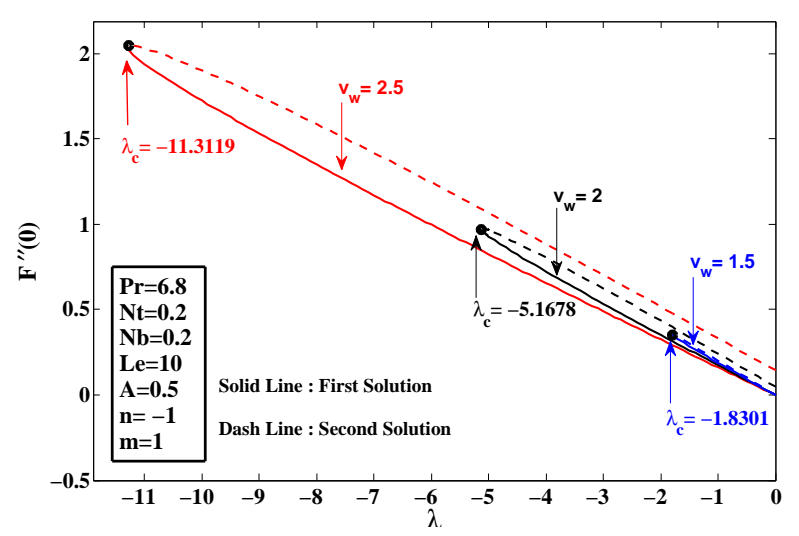

Figure 6: Variation of $f^{\prime \prime}(0)$ with the shrinking parameter $\lambda$ for different values of transpiration rate parameter $V_{w}$.

\subsection{Multiple solutions for shrinking plate}

Figures $2-7$ show the variation of $f^{\prime \prime}(0)$ and $1 / \theta(0)$ versus the shrinking parameter $\lambda$ for different values of the firstorder slip parameter $(m)$, the second-order slip parameter $(n)$ and transpiration rate parameter $\left(V_{w}\right)$. These figures

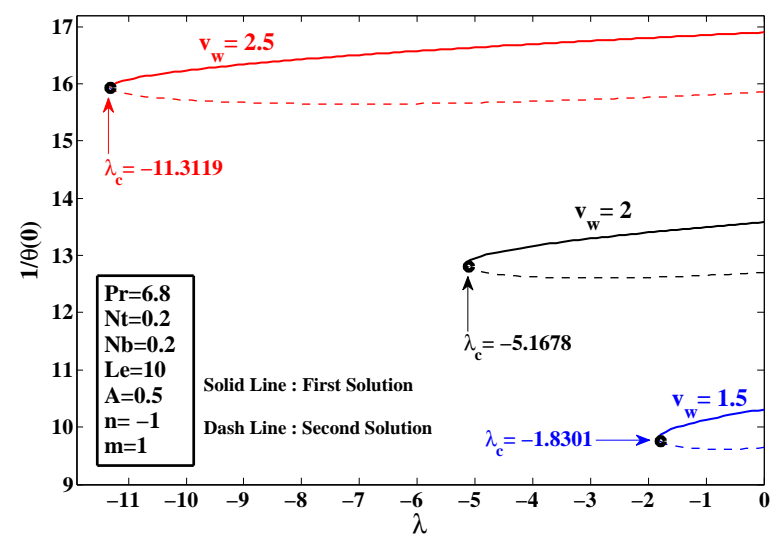

Figure 7: Variation of $1 / \theta(0)$ with the shrinking parameter $\lambda$ for different values of transpiration rate parameter $V_{w}$.

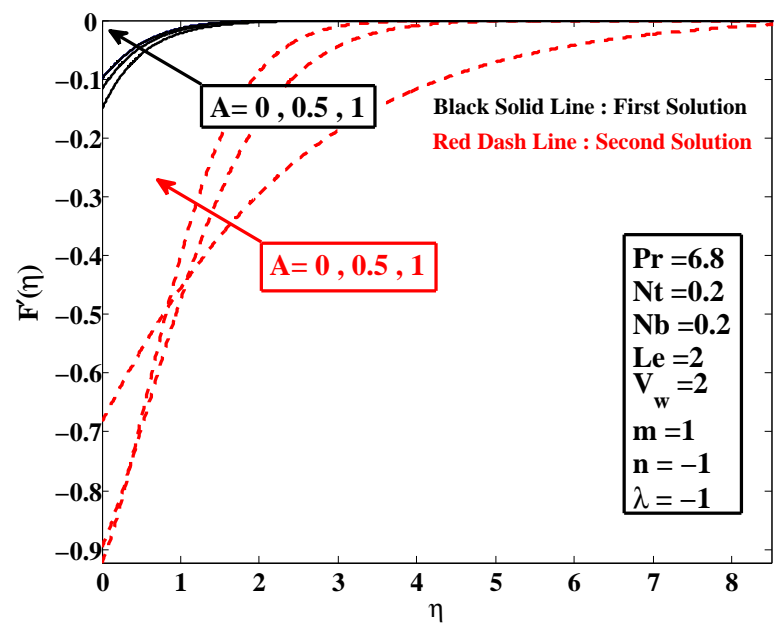

Figure 8: First and second solutions of velocity profile $f^{\prime}(\eta)$ for different values of unsteadiness parameter $A$.

demonstrate that the number of solutions depend on the shrinking parameter $\lambda$. In more details, one can observe that the range of the shrinking parameter $\lambda$ for which the solution exist increases with $m,|n|$ and $V_{w}$ and it is pos- 


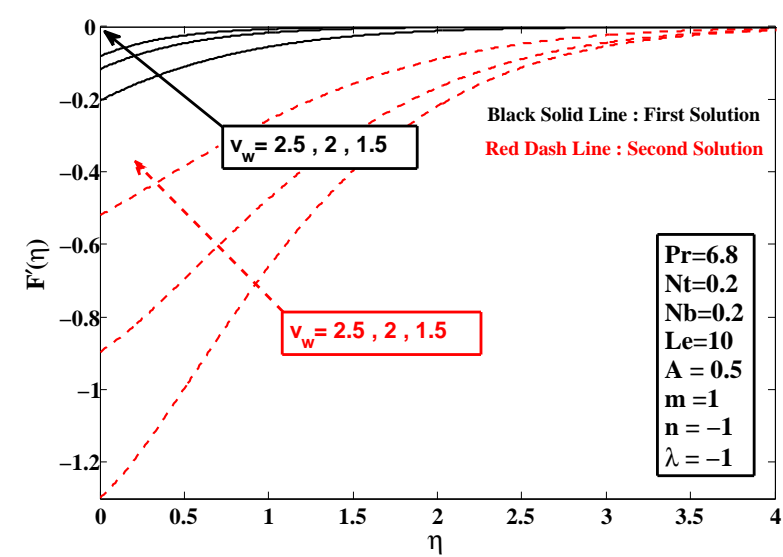

Figure 9: First and second solutions of velocity profile $f^{\prime}(\eta)$ for different values of transpiration rate parameter $V_{w}$.

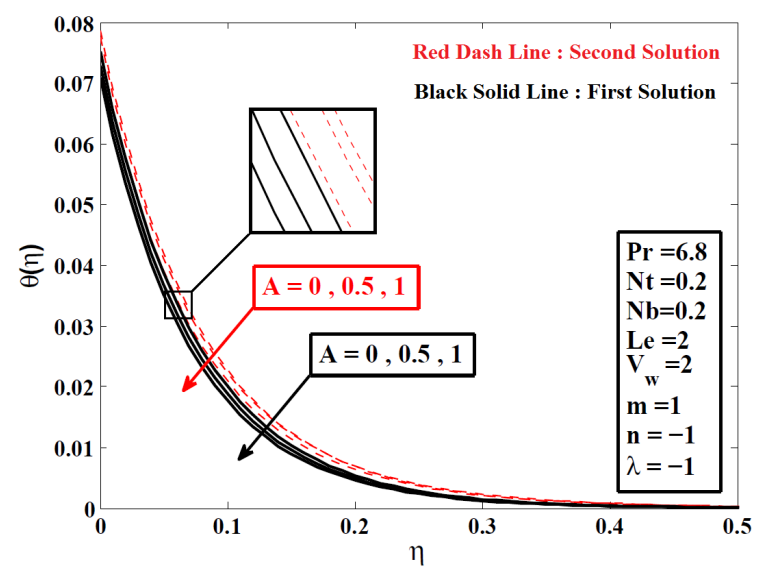

Figure 10: First and second solutions of temperature profile $\theta(\eta)$ for different values of unsteadiness parameter $A$.

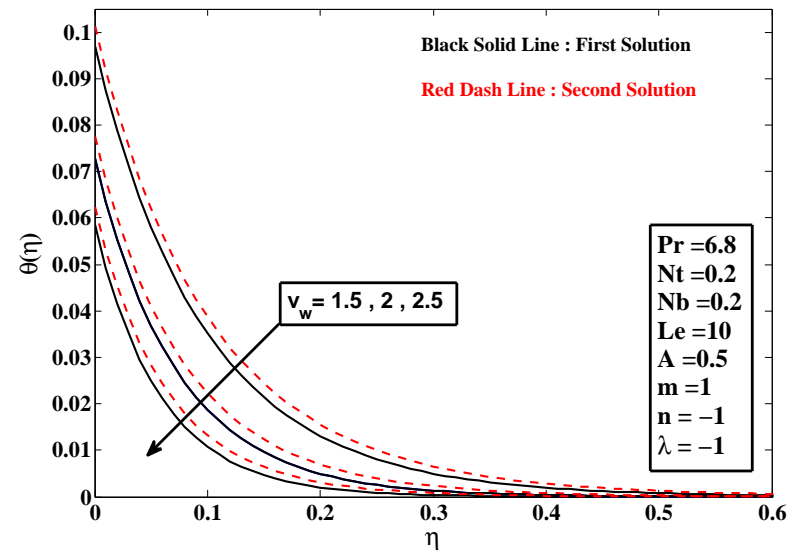

Figure 11: First and second solutions of temperature profile $\theta(\eta)$ for different values of transpiration rate parameter $V_{w}$.

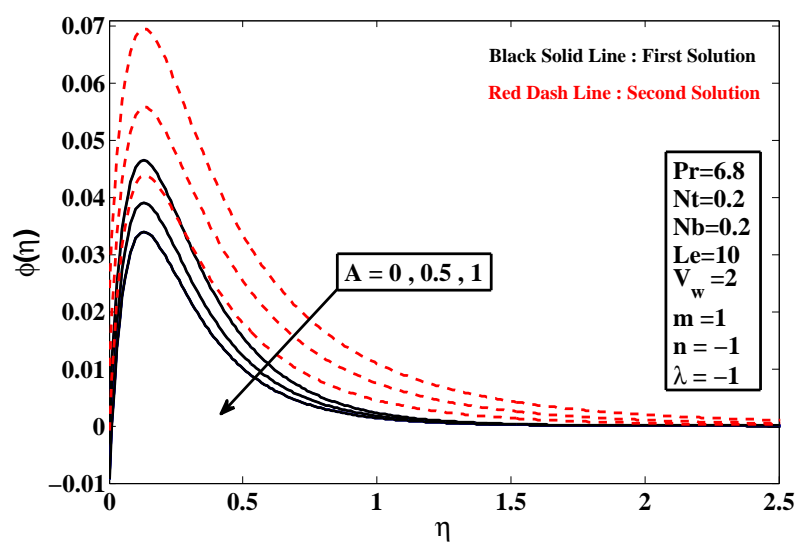

Figure 12: First and second solutions of concentration profile $\phi(\eta)$ for different values of unsteadiness parameter $A$.

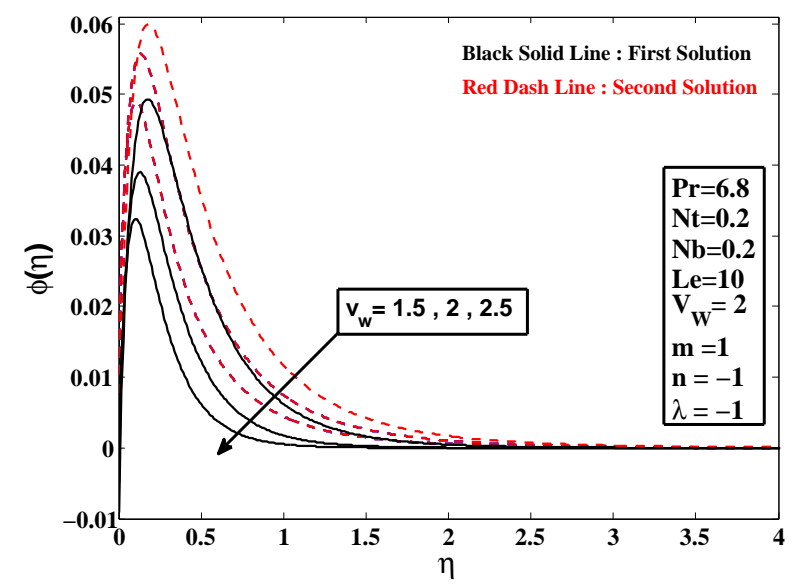

Figure 13: First and second solutions of concentration profile $\phi(\eta)$ for different values of transpiration rate parameter $V_{w}$.

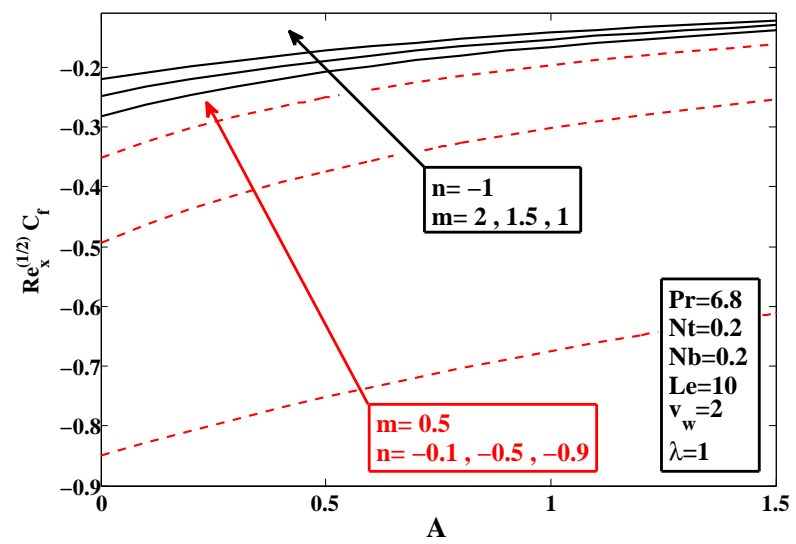

Figure 14: Effect of first-order slip parameter $m$ and second-order slip parameter $n$ on skin friction $\operatorname{Re}_{x}^{1 / 2} C_{f}$. 


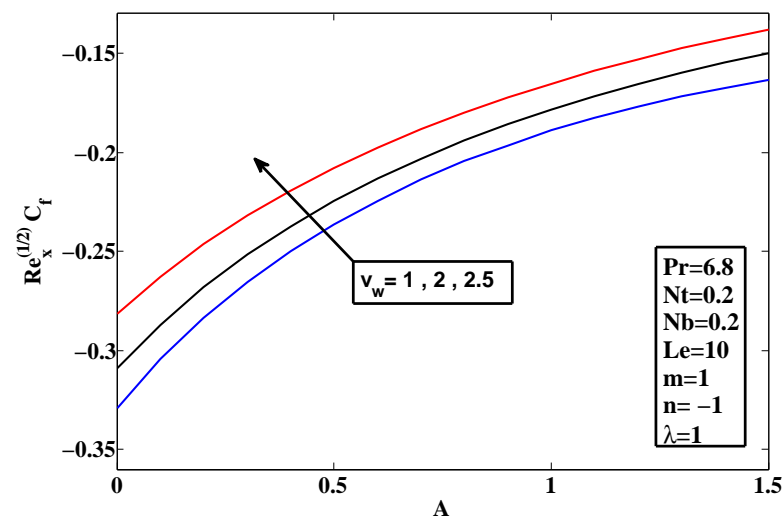

Figure 15: Effect of transpiration rate parameter $V_{w}$ on skin friction $R e_{X}^{1 / 2} C_{f}$.

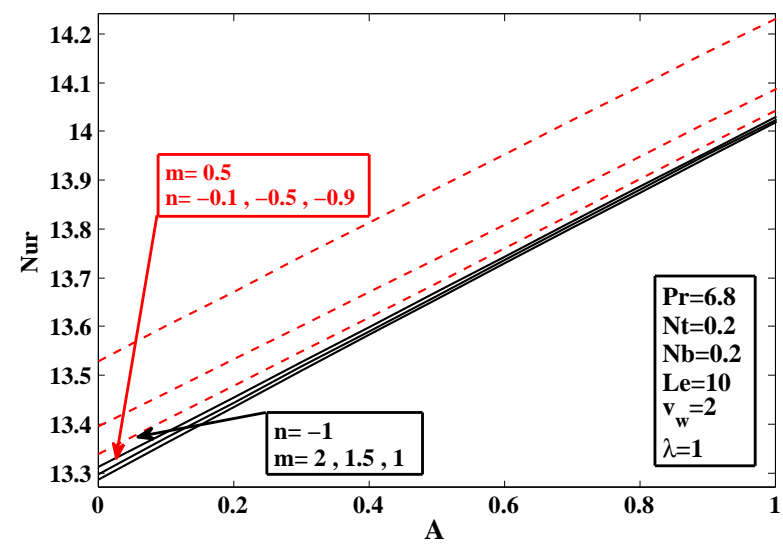

Figure 16: Effect of first-order slip parameter $m$ and second-order slip parameter $n$ on the reduced Nusselt number Nur.

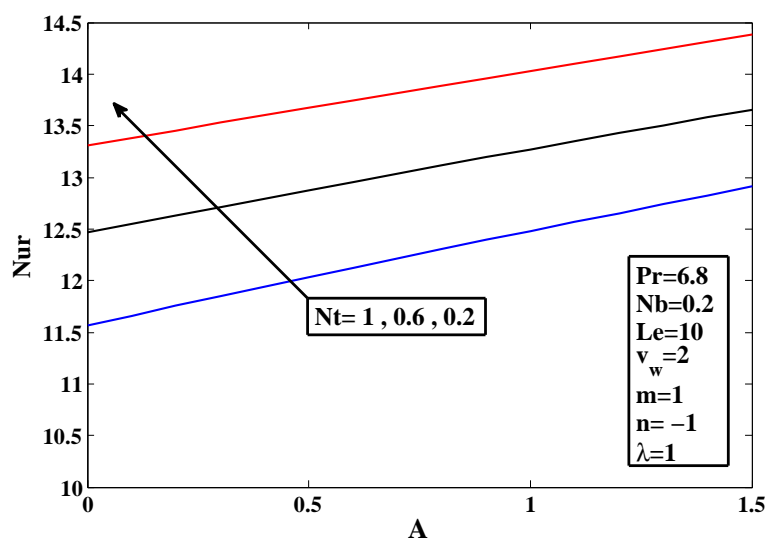

Figure 17: Effect of thermophoresis parameter $N t$ on the reduced Nusselt number Nur.

sible to obtain dual solutions for the similarity equations (23)-(25). It is seen that the solution exists up to a critical value of $\lambda$ (say $\lambda_{c}$ ), with two solution branches for $\lambda>\lambda_{c}$, a saddle-node bifurcation at $\lambda=\lambda_{c}$ and no solutions for $\lambda<\lambda_{c}$. To determine the stability of the dual solutions, we solve the eigenvalue problem (42)-(45) and find the smallest eigenvalue $y$. Positive value of $y$ results in an initial decay and the flow is stable while negative value implies the growth of disturbance and the flow is unstable. The smallest eigenvalues $y$ for various values of $\lambda$, when $N t=N b=$ $0.2, V_{w}=2, A=0.5, n=0, m=0.01, L e=10$ and $\operatorname{Pr}=6.8$ are presented in Table 2 . The results indicate that $y$ is positive for the upper branch (first) solution and negative for the lower branch (second) solution. So, the upper branch solution is stable, while the lower branch is not. From Figures 2, 3, 6 and 7, the magnitude of $\left|\lambda_{c}\right|$, are smaller when the second-order slip parameter is absent $(n=0)$ compared to the corresponding values when it is present $(n=-1)$. Figures 7 and 8 illustrate the critical values of $\lambda$ are $\lambda_{c}=-1.8301,-5.1678$ and -11.3119 for $V_{w}=1.5,2$, and 2.5 , respectively. Thus, $\left|\lambda_{c}\right|$, increases with the increase of the transpiration rate parameter $\left(V_{w}\right)$. The values of $f^{\prime \prime}(0)$ decrease with the increase of the firstorder slip parameter $(m)$ as well as with the increase of $|n|$. (see Figures 2 and 4). On the other hand, the values of $1 / \theta(0)$ increase with the increase of both $m$ and $|n|$ as can be seen from Figures 3 and 5, respectively.

Table 2: The smallest eigenvalues $y$ for various values of $\lambda$, when $N t=N b=0.2, V_{w}=2, A=0.5, n=0, m=0.01, L e=$ 10 and $\operatorname{Pr}=6.8$.

\begin{tabular}{ccc}
\hline$\lambda$ & Upper branch & Lower branch \\
\hline-0.55 & 1.456 & -1.235 \\
-0.65 & 1.125 & -0.941 \\
-0.75 & 0.682 & -0.587 \\
-0.80 & 0.596 & -0.528 \\
-0.85 & 0.513 & -0.489 \\
-0.90 & 0.448 & -0.415 \\
-0.92 & 0.374 & -0.357 \\
-0.94 & 0.301 & -0.291 \\
-0.95 & 0.236 & -0.229 \\
-0.955 & 0.179 & -0.168 \\
-0.958 & 0.129 & -0.121 \\
-0.9599 & 0.034 & -0.034 \\
\hline
\end{tabular}

\subsection{Boundary layers behavior with focus on shrinking plate case}

Figures 8-13 show the velocity, temperature and concentration profiles, for different values of unsteadiness parameter $(A)$ and transpiration rate parameter $\left(V_{w}\right)$. What can be noted from these figures is that the profiles for both first and second solutions is satisfactory for the far field 
boundary conditions asymptotically, and concur the results of numerical solution of Section 4.1. It is also manifest that the profiles of the second solution have a much higher boundary layer thickness which implies that the top diagrams (black sold lines) are the stable solution as opposed to the bottom diagrams (red dash lines) solution.

Figures 8 and 9 indicate that as the values of the unsteadiness parameter $(A)$ and transpiration rate parameter $\left(V_{w}\right)$. increase, the velocity of boundary layer in either solution would increase as well, which suggests that the hydrodynamic boundary layer thickness would be thinner when the amplitude of unsteadiness parameter increases. However, it is worth mentioning that the matter is not acceptable for the unsteadiness parameter effect near the wall, when there is a reversed flow near the wall for the second solutions. As a result, when the transpiration rate parameter $\left(V_{w}\right)$ increases, the thickness of the hydrodynamic boundary layer decreases. This phenomenon is in accordance to that of a viscous fluid. Hence, regardless of the types of fluids, viscous fluid or nanofluid, suction always would lead to stabilization of the boundary layer grow. Moreover, in this research, the suction case $\left(V_{w}>0\right)$ has been applied, since in the boundary layer definition, it is basically assumed that the boundary layer thickness is supposed to be practically very thin.

On the other hand, as the unsteadiness parameter $(A)$ and transpiration rate parameter $\left(V_{w}\right)$ raise, the temperature profiles of the both solutions is compressed which is shown in Figures 10 and 11 respectively. Therefore, when unsteadiness parameter $(A)$ and transpiration rate parameter $\left(V_{w}\right)$ enhance, the thickness of the thermal boundary layer for the both first and second solutions decreases Figure 11 depicts the second solution of the temperature when there is heat generation inside the boundary layer, which is impossible while the viscous dissipation effects has not been considered in the present model. This matter also can be other reason to decline the second solution of problem.

Figures 12 and 13 illustrate the effect of the unsteadiness parameter $(A)$ and transpiration rate parameter $\left(V_{w}\right)$ on the nanoparticles concentration profile. What we noticed here was that, these profiles increase near the surface of the shrinking sheet and climax to its maximum before falling to its ambient value zero. This effect might come from thermophoresis effect on the concentration boundary condition $N b \phi^{\prime}(0)+N t \theta^{\prime}(0)=0$. As the transpiration rate parameter $\left(V_{w}\right)$ intensifies, nanoparticles concentration profiles would decrease which are pertaining to the lower and upper branch solutions.

\subsection{Skin friction coefficient and Nusselt number with focus on stretching plate case}

Figures 14 and 15 depict the skin friction $\operatorname{Re}_{x}^{1 / 2} C_{f}$ for different values of the first-order slip parameter $(m)$, the secondorder slip parameter $(n)$ and transpiration rate parameter $\left(V_{w}\right)$ versus the unsteadiness parameter $(A)$ between 0 to 1.5. Figures 14 and 15 demonstrate that skin friction enhance with increasing the unsteadiness parameter $(A)$. Moreover, from Figure 14, the skin friction coefficient reduces slightly with the first order slip parameter $(m)$ and increase more strongly with the absolute value of the second order slip parameter $(|n|)$. Besides, the Figure 15 depicts that the suction increases values of the skin friction coefficient that is a predictable topic in the problem conditions. In fact, the boundary layer thickness decreases with transpiration rate parameter $\left(V_{w}\right)$, where this matter enhances velocity gradient on the wall. Consequently, one can predict a higher skin fiction with the increase in transpiration rate parameter $\left(V_{w}\right)$.

Figures 16 and 17 are made to reveal the ramifications of the first-order slip parameter $(m)$, the second-order slip parameter $(n)$, the unsteadiness parameter $(A)$ and thermophoresis parameter $(N t)$ on the reduced Nusselt numberNur(the rate of heat transfer at the surface). An increasing manner of the reduced Nusselt number Nur with the unsteadiness parameter $(A)$ can be concluded from Figures 16 and 17. On the other hand, Figure 16 demonstrates that the declined Nusselt numberNurlessens with both the first-order slip parameter $(m)$ and the absolute value of the second-order slip parameter $(|n|)$. The effects of the thermophoresis parameter $(N t)$ on the reduced Nusselt number Nur for the different unsteadiness parameter $(A)$ is depicted in Figure 17. Obviously, it is observed that the reduced Nusselt number Nur decrease as the thermophoresis parameter $(\mathrm{Nt})$ decreases, which was already reported by Dinarvand et al. [5,9]. Consequently, the greatest heat transfer rate is observed for the situation in which the thermophoresis parameter $(N t)$ is very small.

\section{Conclusions}

In this article, the effects of second-order slip on unsteady convective boundary layer flow of a Buongiorno's nanofluid (in which nanoparticles' Brownian motion and thermophoresis effects have been considered) along a permeable shrinking/stretching plate in the presence of suction has been investigated. The similarity solution is em- 
ployed to reduce the governing system of partial differential equations to nonlinear ordinary differential equations with the aim of solving them numerically by the Keller-box method (KBM). The study has been focused on: (1) the multiple solutions, (2) the boundary layers behavior and (3) the skin friction and heat transfer.

The main outcomes resulting from this research are as follows. (1) The shrinking parameter $\lambda$ determines how many solutions the problem would have. Physical parameters would change the range of $\lambda$ in which the solution exist and multiple solutions can be achieved by solving similarity equations. (2) The application of first and second order slips at the wall cause the critical suction parameter to decrease. (3) For shrinking plate, as unsteadiness effects increase, the velocity component enhances, whereas the concentration of particles and the temperature profiles decline. (4) The influence of the unsteadiness on the nanoparticles concentration profiles turns out to be more outstanding as opposed to the velocity and temperature profiles. (5) It is necessary to consider the second order slip in modeling a nanofluid because the second order slip would amplify the rate of shear stress at the wall, and also reduces the heat transfer rate in a nanofluid. (6) The thermophoresis and the Brownian motion effects were found to be key factors in the growth of heat transfer. The highest values are obtained when thermophoresis is very small and approaches to zero.

Acknowledgements: The authors wish to thank the reviewers for their careful, unbiased and constructive suggestions, which led to this revised manuscript.

\section{References}

[1] Choi S.U.S., Enhancing thermal conductivity of fluids with nanoparticles, Proc. 1995 ASME Int. Mech. Eng. Congr. Expo., San Francisco, USA, ASME, FED 231/MD 66, 1995, 99-105.

[2] Choi S.U.S., Zhang Z.G., Yu W., Lockwood F.E., Grulke E.A., Anomalously thermal conductivity enhancement in nanotube suspensions, Appl. Phys. Lett., 2001, 79, 2252-2254.

[3] Nademi Rostami M., Dinarvand S., Pop I., Dual solutions for mixed convective stagnation-point flow of an aqueous silica -alumina hybrid nanofluid, Cn. J. Phys., 2018, 56, 2465-2478.

[4] Dinarvand S., Hosseini R., Tamim H., Damangir E., Pop I., Unsteady three-dimensional stagnation-point flow and heat transfer of a nanofluid with thermophoresis and Brownian motion effects, J. Appl. Mech. Tech. Phys., 2015, 56, 601-611.

[5] Dinarvand S., Hosseini R., Pop I., Axisymmetric mixed convective stagnation-point flow of a nanofluid over a vertical permeable cylinder by Tiwari-Das nanofluid model, Powder. Tech., 2017, 311, 147-156.

[6] Oztop H.F., Abu-Nada E., Numerical study of natural convection in partially heated rectangular enclosures filled with nanofluids, Int. J. Heat Fluid Flow, 2008, 29, 1326-1336.

[7] Buongiorno J., Convective transport in nanofluids, ASME J. Heat Transfer., 2006, 128, 240-250.

[8] Tiwari R.J., Das M.K., Heat transfer augmentation in a twosided lid-driven differentially heated square cavity utilizing nanofluids, Int. J. Heat Mass Transfer, 2007, 50, 2002-2018.

[9] Dinarvand S., Hosseini R., Abulhasansari., Pop I., Buongiorno's model for double-diffusive mixed convective stagnation-point flow of a nanofluid considering diffusiophoresis effect of binary base fluid, Advanced Powder Technology, 2015, 26, 1423-1434.

[10] Nield D.A., Kuznetsov A.V., The Cheng-Minkowycz problem for natural convective boundary-layer flow in a porous medium saturated by a nanofluid, Int.J. Heat Mass Transfer, 2009, 52, 5792-5795.

[11] Grosan T., Pop I., Forced convection boundary layer flow past a nonisothermalthin needles in nanofluids, ASME, J. Heat Transfer, 2011, 133, 054503.

[12] Tamim H., Dinarvand S., Hosseini R., Rahimi H., Pop I., Steady laminar mixed convection stagnation-point flow of a nanofluid over a vertical permeable surface in the presence of a magnetic field, J. Appl. Mech. Tech. Phys., 2016, 57, 1031-1041.

[13] Dinarvand S., Pop I., Free-convective flow of copper/water nanofluid about a rotating down-pointing cone using TiwariDas nanofluid scheme, Advanced Powder Technology, 2017, 28, 900-909.

[14] Sheremet M.A., Dinarvand S., Pop I., Effect of thermal stratification on free convection in a square porous cavity filled with a nanofluid using Tiwari and Das'nanofluid model, Physica E: Low-Dimensional Systems and Nanostructures, 2015, 69, 332-341.

[15] Maïga S.E.B., Palm S.J., Nguyen C.T., Roy G., Galanis N., Heat transfer enhancement by using nanofluids in forced convection flows, Int. J. Heat Fluid Flow, 2005, 26, 530-546.

[16] Bachok N., Ishak A., Pop I., Boundary-layer flow of nanofluids over a moving surface in a flowing fluid, Int. J. Therm. Sci., 2010, 49, 1663-1668.

[17] Khan W.A., Pop I., Boundary-layer flow of a nanofluid past a stretching sheet, Int. J. Heat Mass Transfer, 2010, 53, $2477-$ 2483.

[18] Kuznetsov A.V., Nield D.A., Natural convective boundary-layer flow of a nanofluid past a vertical plate, Int. J. Therm Sci., 2010, 49, 243-247.

[19] Tamim H., Dinarvand S., Hosseini R., Khalili S., Pop I., Unsteady mixed convection flow of a nanofluid near orthogonal stagnation-point on a vertical permeable surface, J. Process Mech. Eng., 2014, 228, 226-237.

[20] Malvandi A., The Unsteady Flow of a Nanofluid in the Stagnation Point Region of a Time-dependent Rotating Sphere, Therm. Sci., 2015, 19, 1603-1612.

[21] Kuznetsov A.V., Nield D.A., Natural convective boundary-layer flow of a nanofluid past a vertical plate: A revised model, Int. J. Therm. Sci., 2014, 77, 126-129.

[22] Bahiraei M., Hosseinalipour S. M., Hangi M., Laminar forced convection of a water-TiO2 nanofluid in annuli considering mass conservation for particles, Chem. Eng. Technol., 2013, 36, 2057-2064.

[23] Dinarvand S., Hosseini R., Pop I., Unsteady convective heat and mass transfer of a nanofluid in Howarth's stagnation point 
by Buongiorno's model, Int. J. Numerical Methods for Heat and Fluid Flow, 2015, 25, 1176-1197.

[24] Rosca A.V., Pop I., Flow and heat transfer over a vertical permeable stretching/shrinking sheet with a second order slip. Int. J. Heat Mass Transfer, 2013, 60, 355-364.

[25] Rana P., Dhanai R., Kumar L., MHD slip flow and heat transfer of Al203-water Nanofluid over a horizontal shrinking cylinder using Buongiorno's model: Effect of nanolayer and nanoparticle diameter, Advanced Powder Technology, 2017, 28, 17271738.

[26] Dhanai R., Rana P., Kumar L., MHD mixed convection nanofluid flow and heat transfer over an inclined cylinder due to velocity and thermal slip effects: Buongiorno's model, Powder Technol., 2016, 288, 140-150.

[27] Dhanai R., Rana P., Kumar L., Lie group analysis for bioconvection MHD slip flow and heat transfer of nanofluid over an inclined sheet: Multiple solutions, J. TW. Inst. Chem. Eng., 2016, 66, 283-291.

[28] Wu L., A slip model for rarefied gas flows at arbitrary Knudsen number. Appl. Phys. Lett., 2008, 93, 253103.

[29] Rosca N.C., Pop I., Mixed convection stagnation point flow past a vertical flat plate with a second order slip: heat flux case, Int. J Heat Mass Transfer, 2013, 65, 102-109.

[30] Fang T., Yao S., Zhang J., Aziz A., Viscous flow over a shrinking sheet with a second order slip flow model, Commun. Nonlin. Sci. Numer. Simul., 2010, 15, 1831-1842.

[31] Dhanai R., Rana P., Kumar L., Multiple solutions in MHD flow and heat transfer of Sisko fluid containing nanoparticles migration with a convective boundary condition: Critical points, Euro. Phys. J. Plus, 2016, 131, 1-14.

[32] Rana P., Shukla N., Gupta Y., Pop I., Homotopy analysis method for predicting multiple solutions in the channel flow with stability analysis, Commun. Nonlin. Sci. Numer. Simul., 2019, 66, 183-193.
[33] Rana p., Uddin M.J., Gupta Y., Ismail A. I. Md., Slip effects on MHD Hiemenz stagnation point nanofluid flow and heat transfer along a nonlinearly shrinking sheet with induced magnetic field: Multiple solutions, J. BR. Soci. Mech. Sci. Eng., 2017, 39, 3363-3374.

[34] Fang T., Yao S., Zhang J., Aziz A., Viscous flow with secondorder slip velocity over a stretching sheet, Zeitschrift fuer Naturforschung A, J. Phys. Sci., 2010, 65, 1087-1092.

[35] Roşca Natalia C., Roşca Alin V., Aly Emad H., Pop I., Semianalytical solution for the flow of a nanofluid over a permeable stretching/shrinking sheet with velocity slip using Buongiorno's mathematical model, Euro. J. Mech. B/Fluids, 2016, 58, 39-49.

[36] Weidman P.D., Kubitschek D.G., Davis A.M.J., The effect of transpiration on self similar boundary layer flow over moving surfaces, Int. J. Eng., 2006, 44, 730-737.

[37] Harris S.D., Ingham D.B., Pop I., Mixed convection boundarylayer flow near the stagnation point on a vertical surface in a porous medium: Brinkman model with slip, Transp. Porous Media, 2009, 77, 267-285.

[38] Keller HB., A new difference scheme for parabolic problems. In: Numerical solutions of partial differential equations, 1970, New York, Academic Press.

[39] Cebeci T., Bradshaw P., Physical and computational aspects of convective heat transfer, 1988, New York, Springer-Verlag.

[40] Ishak A., Nazar R., Pop I., Post-stagnation-point boundary layer flow and mixed convection heat transfer over a vertical, linearly stretching sheet. Arch Mech, 2008, 60, 303-322.

[41] Pantokratoras A., A common error made in investigation of boundary layer flows, Applied Mathematical Modeling, 2009, 33, 1, 413-422. 


\section{Nomenclature}

\begin{tabular}{|c|c|c|c|}
\hline$A$ & unsteadiness parameter & $u$ & velocity along the plate \\
\hline C & nanoparticle volume fraction & $u_{w}(x)$ & surface velocity \\
\hline$C_{f}$ & friction coefficient & $u_{\text {slip }}(x)$ & slip velocity at the surface \\
\hline$C_{w}$ & nanoparticles volume fraction at the wall & $v$ & velocity normal to the plate \\
\hline$C_{\infty}$ & ambient nanoparticle volume fraction & $v_{w}(x)$ & mass flux velocity \\
\hline $\begin{array}{l}D_{B} \\
D_{T}\end{array}$ & $\begin{array}{l}\text { Brownian diffusion coefficient } \\
\text { thermophoretic diffusion coefficient }\end{array}$ & $x, y$ & Cartesian coordinates \\
\hline$f$ & dimensionless stream function & & \\
\hline$k n$ & Knudsen number & & \\
\hline$k$ & effective thermal conductivity of the nanofluid & \multicolumn{2}{|c|}{ Greek symbols } \\
\hline$L$ & characteristic length & $\alpha$ & thermal diffusivity \\
\hline Le & Lewis number & $\lambda$ & shrinking parameter \\
\hline$m$ & first-order slip parameter & $\tau$ & shear stress and new dimensionless time variable \\
\hline$n$ & second-order slip parameter & $\rho$ & density of the nanofluid \\
\hline $\mathrm{Nb}$ & Brownian motion parameter & $(\rho c)_{f}$ & heat capacity of the base fluid \\
\hline$N t$ & thermophoresis parameter & $(\rho c)_{p}$ & effective heat capacity of nanoparticle \\
\hline $\mathrm{Nu}$ & Nusselt number & $\mu$ & dynamic viscosity of nanofluid \\
\hline $\operatorname{Pr}$ & Prandtl number & $v$ & kinematic viscosity of nanofluid \\
\hline$q_{m}$ & mass flux & $\psi$ & stream function \\
\hline$q_{w}$ & heat flux & $\eta$ & similarity variable \\
\hline$R e_{x}$ & local Reynolds number & $\theta$ & dimensionless temperature \\
\hline Sh & Sherwood number & $\phi$ & dimensionless nanoparticle volume fraction \\
\hline$T$ & fluid temperature & $y$ & $\begin{array}{l}\text { parameter } \\
\text { panorlutio and elgenvalue }\end{array}$ \\
\hline$T_{w}$ & temperature at the wall & $\delta$ & molecular mean free path \\
\hline$T_{\infty}$ & temperature of the ambient fluid & $\sigma$ & momentum accommodation coefficient \\
\hline
\end{tabular}

